\title{
The multiple intelligence classification of management graduates using Two-step cluster analysis
}

\author{
Noorazilah Mohamed* and Siti Rahmah Awang \\ Human Resource Development, Faculty of Management, Universiti Teknologi Malaysia, 81310 UTM Johor Bahru, Johor, Malaysia. \\ *Corresponding Author: noorazilah@utem.edu.my
}

\section{Article history : \\ Received 7 October 2014 \\ Accepted 12 March 2015}

\section{GRAPHICAL ABSTRACT}

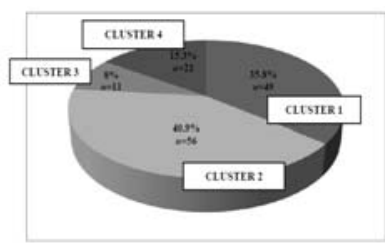

\begin{abstract}
In this study, the multiple intelligence profile of graduates are the main interest in order to enhance the opportunities of management graduates for secure employment. In order to measure and classify the multiple intelligence of graduates, Two-step cluster analysis is applied. The cluster is based on the graduates' demographic background and Gardner's nine intelligences namely musical, spatial/visual, verbal/linguistic, mathematics/logical, bodily-kinaesthetic, interpersonal, intrapersonal, naturalist and spiritual. The framework and findings of this study are conducted at Faculty of Technology Management and Technopreneurship (FPTT), Universiti Teknikal Malaysia Melaka (UTeM). The nine intelligence types of the 137 management graduates had been successfully clustered into four more meaningful clusters based on their intelligence scores and characteristics that agree with Gardner's Multiple Intelligence theory.
\end{abstract}

Keywords: Multiple intelligence, management graduates, two step cluster analysis, SPSS.

(C) 2015 Penerbit UTM Press. All rights reserved http://dx.doi.org/10.11113/mjfas.v11n1.351

\section{INTRODUCTION}

According to the Theory of Multiple Intelligence, individual are unique from one another in terms of the specific profile that he or she exhibits. In addition, Gardner implies that everyone has the capacity for all of the intelligences but develops each intelligence to varying levels [1]. The definition of Multiple Intelligence in this study is focused more on the intelligence profile of management graduates for job placement purposes based on Gardner's nine intelligences namely musical, bodilykinaesthetic, mathematical/logical, spatial, linguistic, interpersonal, intrapersonal, naturalist and spiritual [2]. In addition, it would assist management graduates to identify their potential multiple intelligences and to enhance the chances of securing employment. Logically, jobs do not focus on a single responsibility but require many kinds of intelligence to accomplish given tasks. Thus, it is important to nurture and polish all of the different kinds of intelligence that graduates possess in order to be successful especially at the workplace [3]. Theory of Multiple Intelligence enables graduates to recognize their unique intellect. Recognizing unique intellect will help to boost confidence, improve academic performance, strengthen intelligence, and examine recommended careers. Multiple intelligence have been used successfully by career development professionals and used by academicians to improve academic performance. In addition, Multiple Intelligence provides valuable information about an individual's intelligence levels and reveals ways to increase learning and employment potential [4]. In this study, graduates multiple intelligence profile is the main focus in enhancing the opportunity for graduates' to gain employment. In order to measure and classify the multiple intelligence of graduates, Two-step cluster analysis is applied.

\section{METHOD}

The SPSS Two-step cluster analysis method form clusters on the basis of either categorical or continuous data [5]. This algorithm method will find the proper number of clusters automatically. Two-step cluster analysis categorises graduates into clusters according to the most salient characteristics. As a result homogenous categories of each graduates characteristics were identified. Two-step cluster analysis is preferred and the types of variables and the relationship are shown in Figure 1. The figure represents independent variables which are the demographic characteristics of the respondents described as gender, ethnic, age, marital status, religion and programmes.

This method consists of a few processes namely Auto Clustering Statistics (Schwarz's Bayesian Criterion (BIC)), Distance Measure (log-likelihood criterion) Chi Square and t-test. Auto Clustering statistics of Schwarz's Bayesian Criterion (BIC) are to determine the appropriate number of clusters according to dataset or examining the number of clusters [5]. BIC methods and formulas are defined as:

$$
\mathrm{BIC}=2 \mathrm{x} \text { In (likelihood) In }(N) \mathrm{x} k
$$


INDEPENDENT VARIABLE

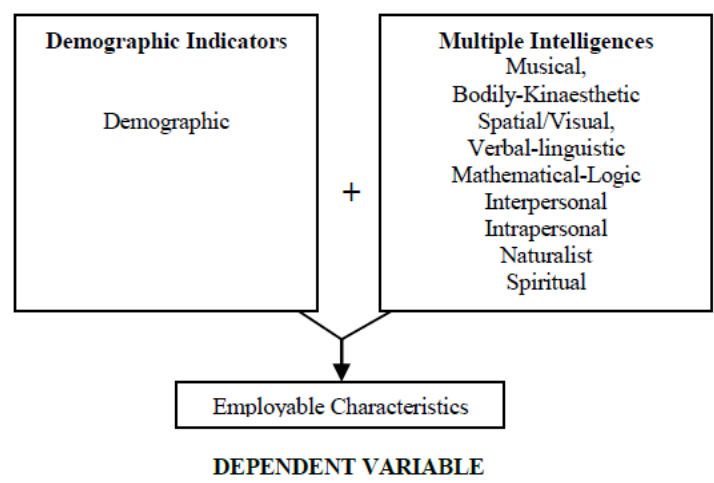

Figure 1 Types of Variable and their Relationship

The BIC is computed for each of the potential clusters, where smaller values indicate better models [6]. Therefore, the smallest BIC is associated with the best cluster formation. Distance Measure (Log-Likelihood Criterion) is used for mixture of continuous and categorical variables. The distance between clusters depends on the decrease in the log likelihood. In calculating log-likelihood, normal distributions for continuous variables and multinomial distributions for categorical variables are assumed [5]. It is also assumed that the variables are independent of each other [5]. By definition, the likelihood function for a statistical model is described as:

$$
L^{*}=\prod_{n=1}^{N} f\left(y_{n} \mid y_{n-1}, y_{n-2}, \ldots, y_{1}, \theta_{1}, \theta_{2}, \ldots \theta_{k}\right)
$$

A chi-square test is a statistical test used for testing independence and goodness of fit. Testing independence determines whether two or more observations across two populations are dependent on each other. Testing for goodness of fit determines if an observed frequency distribution matches a theoretical frequency distribution. In both cases the equation to calculate the chi-square statistic is:

$$
\mathrm{x}^{2}=\sum \frac{(\mathrm{O}-\mathrm{E})^{2}}{\mathrm{E}}
$$

The independent t-test evaluates the difference between the means of two independent or unrelated groups. The test evaluates whether the means for two independent groups are significantly different from each other. The formula for calculating independent sample is shown below.

$$
t=\frac{\bar{x}_{1}-\bar{x}_{2}}{\sqrt{\left(s_{1}^{2} / n_{1}+s_{2}^{2} / n_{2}\right)}}
$$

\section{RESULTS AND DISCUSSION}

The number of clusters can be automatically determined. Bayesian Information Criterion (BIC) was computed in the first phase and resulted in a good initial estimation of the maximum number of clusters. Table 1 presents the auto-clustering statistics of BIC to determine the appropriate number of clusters. The Auto-clustering table summarizes the process by which the number of clusters is chosen. The BIC was computed for each potential cluster, where smaller values indicate better models. In Table 1 the large value decrease from 1716.9 in Cluster 3 to 1700.4 in Cluster 4, suggesting that the most appropriate number of clusters is four.

Table 1: Schwarz's Bayesian Clustering Statistics

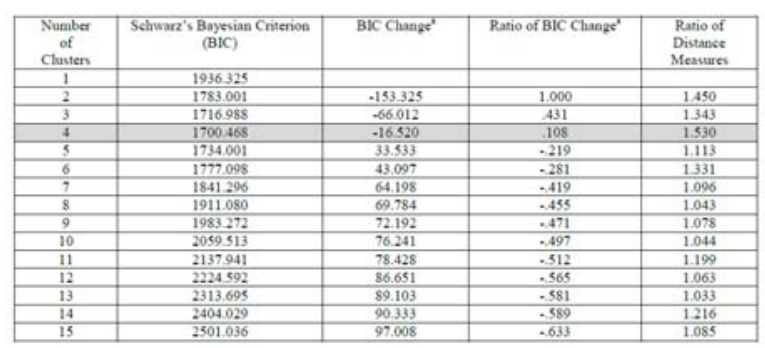

The result from $\mathrm{BIC}$ in Table 2 presents the number of cases in the final solution. The Cluster Distribution table shows the number of cases in each cluster is shown in Table 2.

Table 2: Cluster Distribution

\begin{tabular}{|c|c|c|}
\hline $\begin{array}{c}\text { Number of } \\
\text { Clusters }\end{array}$ & $\boldsymbol{n}$ & Percent (\%) \\
\hline 1 & 49 & 35.8 \\
\hline 2 & 56 & 40.9 \\
\hline 3 & 11 & 8 \\
\hline 4 & 21 & 15.3 \\
\hline Total & $\mathbf{1 3 7}$ & $\mathbf{1 0 0}$ \\
\hline
\end{tabular}

The cluster distribution table shows the frequency of each cluster. Of the 137 total cases assigned to clusters, $n=49$ were assigned to the first cluster, $n=56$ to the second, $n=11$ to the third and $n=21$ to the fourth cluster. Results indicated by the cluster distributions in Table 2 have shown that the largest cluster has $n=56(40.9 \%)$ in Cluster 2 and smallest cluster has $n=11(8 \%)$ in Cluster 3 . The pie chart below summarizes data from cluster distribution as per Figure 2.

Composition of Clusters: Chi square or t-test of significance produces Chi Square statistics indicating the importance of a category of variables and t-test indicating the importance of a continuous variable. The importance of the category of variable is measured based on the Chi Square values of the thirteen variables as per Figure 3 [a] for Cluster 1; Figure 3 [b] for Cluster 2; Figure 3 [c] for Cluster 3 and Figure 3 [d] for Cluster 4 . The values of the Chi Square statistics were determined when the variables exceeded the critical value line. The critical value line that is drawn provides some indication of how dissimilar each cluster is from the average. If the absolute value of the statistic for a cluster is greater than the critical value, the variable is probably important in distinguishing that cluster from the others. For categorical variables (gender, marital status, ethnics, religion and level of intelligence), instead of plots of chi-square values, the variables can get 
plots of t-test that compare the mean of the variable in the cluster to the overall mean at the $\alpha=0.05$ level of significance in the Two Step Cluster Plots dialog box in order to get the critical value lines plotted.

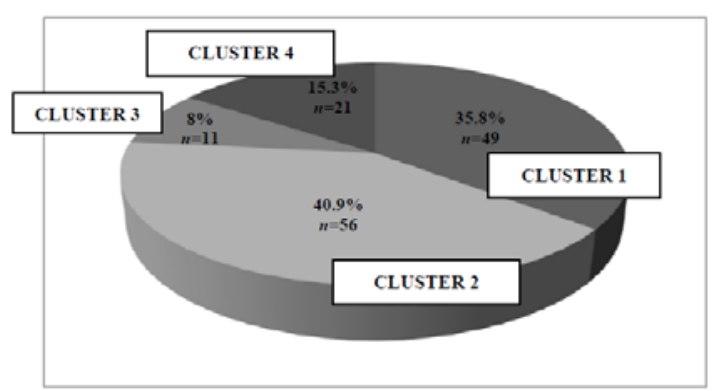

Figure 2: Distribution of Cases by Cluster

Figure 3 [a] for Cluster 1 has shown ethnicity, religion, musical, verbal are important and significant variables with which to form a cluster. For Cluster 2 (Figure $3[\mathrm{~b}]$ ) only musical, verbal and spatial exceed the critical value line. Meanwhile, Figure 3 [c] indicates that Cluster 3 has ten significant variables (ethnicity, religion, musical, kinaesthetic, verbal, spatial, interpersonal, intrapersonal, naturalist and spiritual) in the cluster formation. Figure 3 [d] represents Cluster 4 with ethnicity and religion exceeding the critical value line and as significant variables

$(\mathrm{p}<0.05)$.

Figure 3 [a] demonstrates that categorical variable importance charts are produced with a separate chart for each cluster. The variables are lined up on the $\mathrm{Y}$ axis, in descending order of importance. The dashed vertical lines mark the critical value for determining the significance of each variable. Since the importance measures for the categorical variables (religion, ethnicity, linguistic and musical) exceed the critical value in this chart, it can be concluded that categorical variable contributed to the formation of the first cluster $(\mathrm{p}<0.05)$.

The chart for Cluster 2 shows that religion, ethnicity, marital, gender, naturalist, kinaesthetic, mathematical, intrapersonal, interpersonal and spiritual are not important to the formation of this cluster $(\mathrm{p}<0.05)$.

The chart for Cluster 3 shows that spiritual, mathematical, musical, linguistic, intrapersonal, naturalist, interpersonal, religion, kinaesthetic and ethnicity are marginally significant $(\mathrm{p}<0.05)$

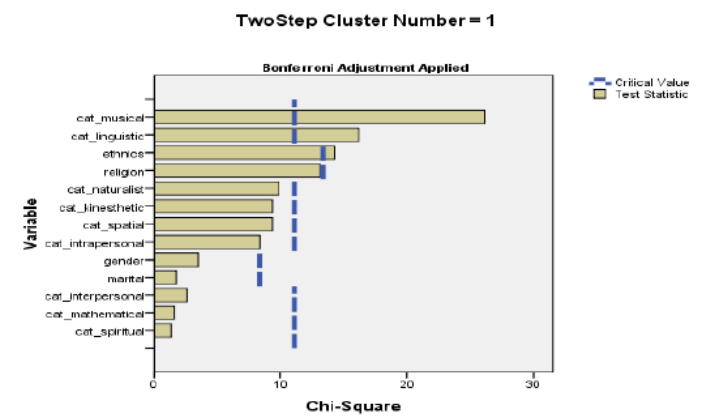

Figure 3 [a]: Importance of category to cluster 1 formation

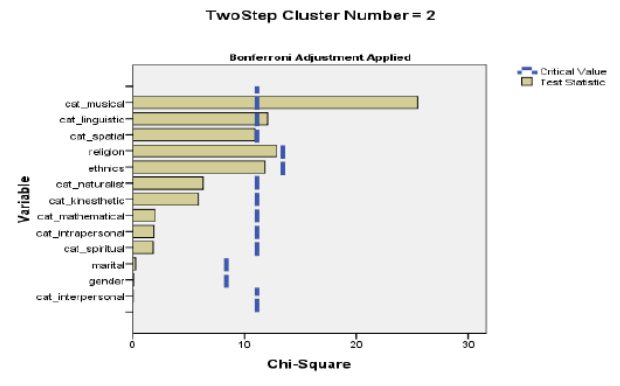

Figure 3 [b]: Importance of category to cluster 2 formation

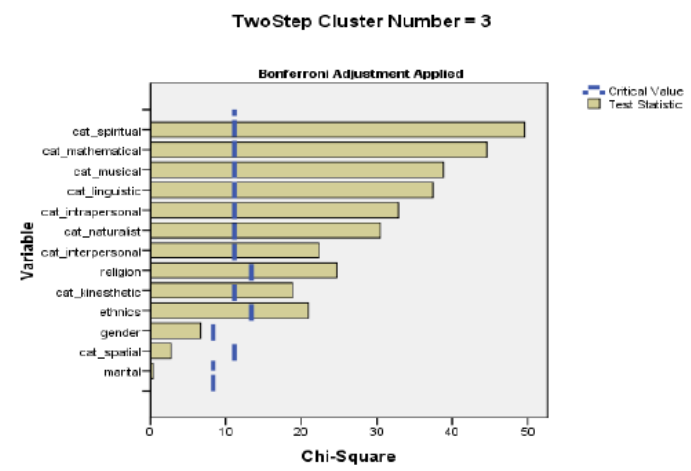

Figure 3 [c]: Importance of category to cluster 3 formation

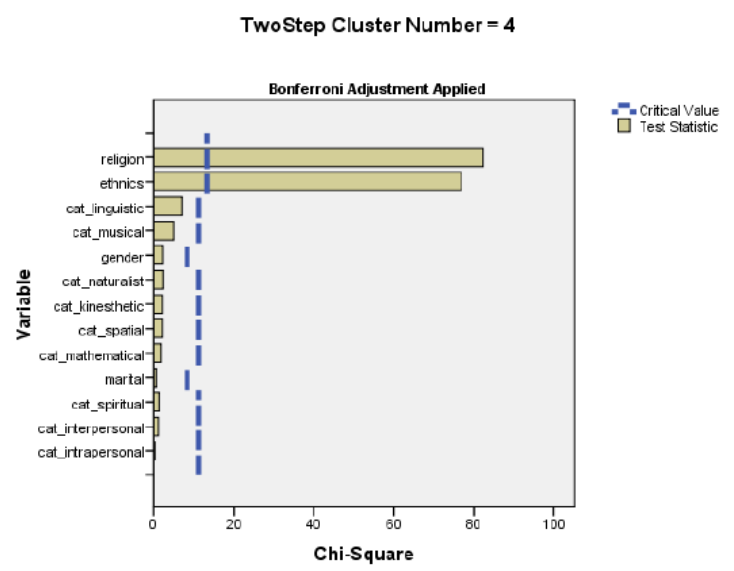

Figure 3 [d]: Importance of category to cluster 4 formation

The chart for Cluster 4 shows that linguistic, musical, gender, naturalist, kinaesthetic, spatial, mathematical, marital status, spiritual, interpersonal and intrapersonal are not important to the formation of this cluster $(\mathrm{p}<0.05)$.

Table 3 summarizes the variables within each cluster based on their importance according to the ChiSquare statistics or t-test of significance. Cluster 1 has four significant variables namely ethnicity, religion, musical and verbal. The analysis also depicts Cluster 2 has three significant variables in intelligence skill (musical, spatial and verbal). Meanwhile, Cluster 3 has ten significant variables (ethnicity, religion, musical, kinaesthetic, spatial, verbal, interpersonal, intrapersonal, naturalist and spiritual). In Cluster 4 there are only two 
significant variables namely ethnicity and religion $(\mathrm{p}<0.05)$.

Table 3 : Summary of Significant Variables $(\mathrm{p}<0.05)$

\begin{tabular}{|c|c|c|c|c|}
\hline Variables & $\begin{array}{c}\text { Cluster } 1 \\
n=49( \\
35.8 \%)\end{array}$ & $\begin{array}{c}\text { Cluster 2 } \\
n=56 \\
(40.9 \%)\end{array}$ & $\begin{array}{c}\text { Cluster } 3 \\
n=11 \\
(8.0 \%)\end{array}$ & $\begin{array}{c}\text { Cluster } 4 \\
n=21 \\
(15.3 \%)\end{array}$ \\
\hline \multicolumn{5}{|l|}{ Categorical data } \\
\hline Gender & No & No & No & No \\
\hline Marital Status & No & No & No & No \\
\hline Ethnics & Significant & No & Significant & Significant \\
\hline Religion & Significant & No & Significant & Significant \\
\hline Programmes & No & No & No & No \\
\hline Musical & Significant & Significant & Significant & No \\
\hline Kinaesthetic & No & No & Significant & No \\
\hline Mathematical & No & No & No & No \\
\hline Spatial & No & Significant & Significant & No \\
\hline Verbal & Significant & Significant & Significant & No \\
\hline Interpersonal & No & No & Significant & No \\
\hline Intrapersonal & No & No & Significant & No \\
\hline Naturalist & No & No & Significant & No \\
\hline Spiritual & No & No & Significant & No \\
\hline $\begin{array}{l}\text { Number } \\
\text { significant of } \\
\text { variables }(p<0.05)\end{array}$ & 4 & 3 & 10 & 2 \\
\hline
\end{tabular}

\section{CONCLUSION}

Cluster 1 was comprised of $n=49$ (35.8\%) Malay Muslim graduates. The majority of the group has high intelligence in musical $n=48(97.96 \%)$ and verbal skill $n=49(100 \%)$. People with musical ability are presented hardworking and having high self-esteem. Another intelligence that comes with musical is verbal ability for Malay graduates [8].

Cluster 2 is characterized by $n=56(40.9 \%)$ of Malay and Non Malays respondents. The majority of the group has high intelligence in spatial skill $n=38$ (60.71\%) and verbal skill $n=32(57.14 \%)$. Spatial skill or visual thinking is an extra skill that enables a person to see and recognize objects, faces and details and this ability is needed by engineers, designers and even successful businessmen [3]. Cluster 2 shows majority of the graduates attain mediocre level $n=34(60.71 \%)$ in musical skill.

Cluster 3 was comprised of $n=11(8 \%)$ graduates. A large percentage are Chinese $n=7(63.64 \%)$ in Cluster 3 which encompasses seven intelligences namely musical, kinaesthetic, spatial, verbal, intrapersonal, naturalist and spiritual. However, most of these intelligences are average in verbal $n=7(63.64 \%)$, and intrapersonal and naturalist with $n=5(45.45 \%)$. In terms of other intelligence, a majority of the graduates display weak/none intelligence in musical $n=6 \quad(54.55 \%)$, kinaesthetic: $n=5(45.45 \%)$ and spatial $n=8(72.73 \%$.). Of these, spiritual skill has the highest percentage. Even though members in Cluster 2 and 3 have several skills, the scores are indistinguishable from to other clusters. Thus, this group is less likely to be employed and faces stiff competition in the job market [6]. Everyone has the capacity for all of the intelligences but develop each intelligence to varying levels and all intelligences have the potential to be developed [2].
Cluster 4 represents $n=21(15.3 \%)$ of graduates. Majority of the group are Chinese $n=12(57.14 \%)$ graduates and consist of other Non-Malay ethnic groups. Even though, the intelligences are insignificant variables forming a cluster, the group cluster obtained high intelligence in Gardner's nine intelligences. Intelligence is not a single, unitary ability but rather a composite of several functions and abilities required for survival and advancement within a particular culture [1].

\section{ACKNOWLEDGEMENTS}

The authors gratefully acknowledge the contributions and assistance of Dean of Faculty Technology Management and Technopreneurship, Universiti Teknikal Malaysia Melaka and the university's administrative staff, who had given full cooperation in providing the data for the study. This work is supported by Research Management Centre, UTM (Vote: 09J74).

\section{References}

[1] Gardner, H. (1983). Frames of Mind. The Theory of Multiple Intelligences. New York: Basic Books.

[2] Gardner, H. (1999). Intelligence Reframed. New York: Basic Books.

[3] Awang, S.R., Aripin, R., Rafia M.H and Ahmad T. (2011). The Classification of Multiple Intelligence of People with Epilepsy. International Conference on Management, Economics and Social Sciences, Bangkok.

[4] Hatch, T. and Gardner, H. (1989).Multiple Intelligences Go To School: Educational Implications of the Theory of Multiple Intelligences.

[5] Norusis, M. J. (2005). SPSS 14.0 Advanced Statistical Procedures Companion. Upper Saddle, NJ: Prentice Hall.

[6] Awang, S. R. Ability Test in Epilepsy Malaysia Patent No 129396 (2008). Universiti Teknologi Malaysia.

[7] Raftery, A. E. (1995). Bayesian Model Selection in Social Research. Social Logical Methodology.

[8] Collingwood, J. (2008). Preferred Music Style to Personality. Psych Central. 